\title{
Sex Dimorphism in Muscle Damage-Induced Inflammation
}

\author{
CASEY APPELL ONE, MOHAMED FOKAR TWO, JAKOB L. VINGREN, FACSM \\ THREE, \& HUI-YING LUK ONE
}

${ }^{1}$ Department of Kinesiology and Sport Management, Texas Tech University, Lubbock, TX. ${ }^{2}$ Center for Biotechnology and Genomics, Texas Tech University, Lubbock TX. ${ }^{3}$ University of North Texas, Denton, TX.

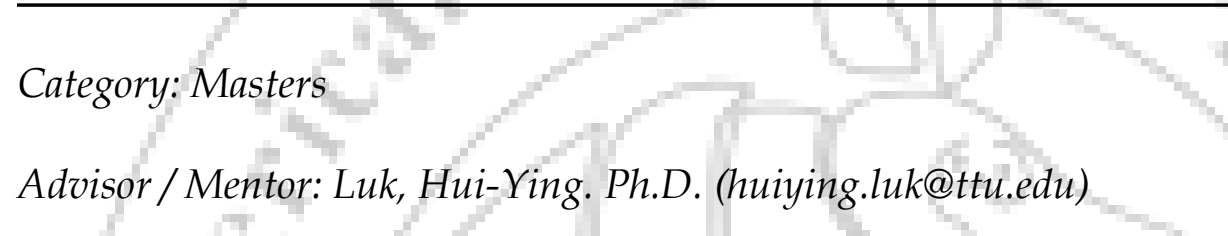

Advisor/Mentor: Luk, Hui-Ying. Ph.D. (huiying.luk@tt
ABSTRACT

Evidence suggests that estrogen can provide a protective effect against muscle damage-induced inflammation. However, to date, no study has directly compared the muscle damage-induced intramuscular cytokines gene expression between men and women. PURPOSE: The purpose was to determine the intramuscular cytokine response to a bout of unaccustomed eccentric exercise in men and women. METHODS: Untrained men $(n=8,22 \pm 3 y)$ and women $(n=8,20 \pm 1 y)$ completed a session of 80 unilateral maximal eccentric knee extensions. Vastus lateralis samples were collected and analyzed for gene expression of Interleukin (IL)-6, IL-10, IL-15, tumor necrosis factor (TNF)- $\alpha$, and transforming growth factor (TGF)- $\beta$ before exercise (BL), and 12 (12h) and 24 hours (24h) after exercise. Data were RESULTS: A significant $(p<0.05)$ time $x$ gender effect was found for IL-10 and TNF-a expression. IL-10 was increased at $12 \mathrm{~h}$ (13.64 \pm 4.22 -fold) and $24 \mathrm{~h}$ (29.34 \pm 8.42 -fold) compared to at BL for men, but there was no change for women. At $24 \mathrm{~h}$, IL-10 was greater for men than for women. Additionally, TNF-a was increased at $24 \mathrm{~h}$ (7.78 \pm 2.17 -fold) compared to $12 \mathrm{~h}$ (3.64 \pm 1.36 -fold) for men; no change was found for women. A significant time effect was found for IL- 6 with an increased at $12 \mathrm{~h}(3.23 \pm 0.7$-fold) and $24 \mathrm{~h}(4.80 \pm 1.57$ fold) compared to BL. No changes were observed for IL-15 and TGF-ß expressions. CONCLUSION: In response to exercise-induced muscle damage, TNF- $\mathrm{a}$ and IL-10 gene expression increased in men but not in women. These results suggest that there is a sex dimorphic response in muscle damage-induced intramuscular pro-inflammatory and anti-inflammatory cytokines.

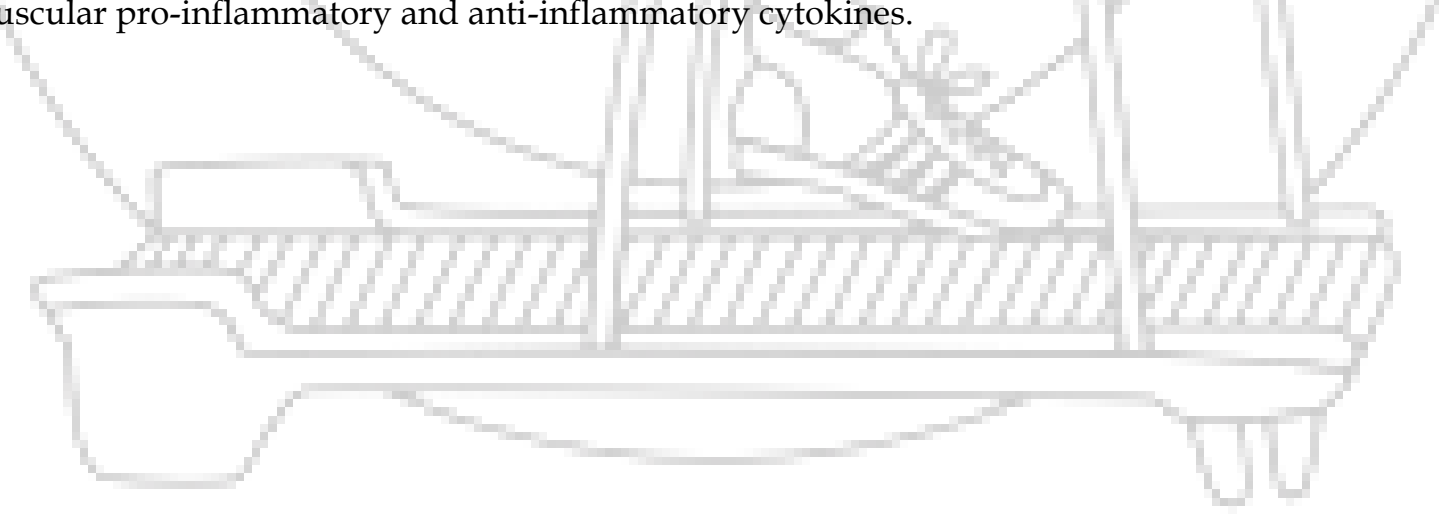

